\title{
Attending to difference: Enacting individuals in food provision for residents with dementia
}

\section{Abstract (161 words)}

In the face of warnings about total institutions and growing concern about the quality of care, health care professionals in Western Europe and North America have increasingly been exhorted to tailor their services to individuals in their care. In this article we invite our readers to become more interested in the kinds of differences care is being tailored to, and with what effects. Focusing on food provision for residents with dementia, we present three repertoires through which care workers attend to, and enact different sets of differences between individuals: providing choice allows residents to express fleeting preferences; knowing residents places emphasis on the care providers' familiarity with a person; and catering to identities brings to the fore the tastes which make up part of who someone is. The analysis brings attending to difference to the fore as a practical process and suggests that tailoring care requires sensitivity to the different kinds of individuals that may be enacted when attending to difference.

\section{Acknowledgements}

This article was written in the cross-over between two research projects at the University of Amsterdam. At the time of writing up, Annelieke Driessen conducted her PhD research as part of the Long-Term Care and Dementia Partnership, and within the wider Anthropology of Care Network. Rebeca Ibañez-Martin held a post-doc position in the ERC-funded project 'Eating bodies in Western practice and theory', which later evolved into the Eating Bodies fluid network emerged that Annelieke 
also came to be part of. Rebeca and Annelieke jointly analysed the fieldwork material, and Annelieke wrote it up, resulting in the current article. We would like to thank both teams and their guests for their support. In particular, for their constructive and valuable feedback, we thank Justine Laurent, Else Vogel, Filipo Bertoni, Annemarie Mol, Marianne de Laet, Andie Thompson and Silke Hoppe. For ever-constructive comments and encouragements we thank Jeannette Pols and Kristine Krause. We are most grateful to all the research participants for teaching us so much about how different differences come to matter. We are furthermore much obliged to Janneke Staaks for getting us started with scoping the literature, and to Ben Belek for comments on the final version. Finally, we are grateful to Steve Russel and Mercedes Duff for carefully editing our English. 


\section{Introduction}

In response to medicalisation and institutionalisation, and a growing concern for the 'voice of the patient', health care professionals are increasingly exhorted to tailor their services to individuals in their care. This shift is reflected in the rapid rise and widespread successes of various branches of the health care sector in Western Europe and North America that are defined by specific and renewed attention to individuals and their uniqueness (Hughes et al. 2008). However, when differences are delineated, they are often made by relating individuals to statistical groups. These groups are defined variously by shared characteristics such as sex, class, religion or age. But what makes an individual? To what differences should health care professionals attend?

A closer look reveals that individuality is enacted differently in different medical settings. Take for instance personalised medicine, a commercial branch of pharmacogenomics that emerged in the 1990s in response to the 'one size fits all' approach used in evidence-based medicine to test the effectiveness of biomedical treatments. Personalised medicine builds on a growing body of scientific research indicating that variability in drug response is largely determined by individual genes (Vogenberg et al. 2010: 565). It seeks to identify different combinations of genes (through, for instance, whole genome sequencing, liquid biopsies or microbiome analysis) and their interaction with 'social factors' (for example lifestyle, socio-economic status or exposure to particulate matter) to tailor treatment to specific individuals (Day et al. 2017: 143-4). Here, individuality lies in a specific genetic profile that makes individuals part of different subgroups with shared genetic characteristics.

By contrast, patient-centred medicine seeks to distance itself from treatment models in which patients are objectified by the medical gaze, focusing instead "on fostering joint understanding of illness and its management" (Hughes et al. 2008: 457). Doctors practising patient-centred medicine, rather than focusing on a localisable 'illness', examine 'the whole person' to come to an 'overall diagnosis'. "This should include everything that the doctor knows and understands about his patient; the patient, in fact, has to be understood as a unique human being" (Balint 1969: 269). Here, 
differences are not located in genes but in biographies, current personal circumstances, abilities and resources.

Individuality is done yet again differently in person-centred care. In the 1990s, Kitwood was a key figure in challenging the 'neurological determinism' (1995: 133) of models of dementia in which individuals were assessed merely on their cognitive functioning. He regarded these models to be reductionist, and proposed the notion of 'personhood'. Kitwood draws on the work of Buber to argue that personhood emerges and is maintained in relationships, interconnection and communication between people (Kitwood 1997). 'The kinds of differences that come to matter here include a person's experiences, their psychological needs and their relationships.

These three approaches to individuality show how medicine does individuality and difference differently and tailors to different things in various practices, such as genes, personal circumstances, and subjective experiences, needs and relationships. Taking this observation as our point of departure, in this article we look at approaches to individuality through the lens of food provision practices in residential care for people with dementia."i

While food provision is an everyday practice in residential care, it is by no means simple to do. In the voluminous body of literature on mealtimes and residential care (e.g. Abbott et al. 2013; Bonnel 1993; Mol 2010; Reimer and Keller 2009), and food, feeding practices and dementia care (e.g. Brijnath 2011; Henkusens et al. 2014; Milte et al. 2017; Watson 1993; Watson and Green 2006), food provision emerges pre-eminently as the practice through which physical nutritional needs are met. At the same time, mealtimes are social events (Mol 2010) in which individuality may be undone (for instance through the universal nature of institutional food) or done (for instance by attending to food preferences, diets or (in)abilities related to taking in food). What is more, adapting care to individual preferences and abilities can make the difference between eating well and eating poorly, and eventually of life and death (Harbers et al. 2002). Empirical attention to details is therefore crucial. We ask: What does care that attends to differences between people actually tailor to? What 
individuality or uniqueness is targeted? What ideals are strived after in different ways of attending to difference?

\section{Methodological commitments}

To answer these questions, we draw on fourteen months of ethnographic fieldwork conducted by Annelieke between April 2013 and July 2015 as part of her PhD project concerned with care and everyday life practices and their enactments of subject positions for people living with dementia (see Driessen, 2019). Prior to the start of fieldwork, the research was approved by the Ethics Board for Social Science Research of the University of Amsterdam.

The fieldwork was conducted on the dementia wards of three residential care homes in the Netherlands, here called De Zonneweide, De Parkhoeve and De Bostuin.iii Access to all locations was obtained via the directors of the care organisations. Staff received information about the study via internal mailings and the organisations' intranet. Residents' family members and partners were informed via the organisational newsletter and told they had the right to object.

Fieldwork consisted of exploratory research in nursing home De Bostuin (10 days over 4 months in 2013), followed by participant observation in care home De Zonneweide (6 months in 2014) and nursing home De Parkhoeve (8 months in 2014 and 2015). De Bostuin is a large-scale nursing home [verpleeghuis] in a more rural setting, and includes two wards, each of which is home to 12 residents with non-congenital brain damage or early-onset dementia. Care workers provided all three meals to the residents. Warm meals were prepared elsewhere, with the exception of one day a month, when residents and care workers cooked together. De Zonneweide is a small-scale care home [verzorgingshuis or woonzorgcentrum], home to 50 residents, out of which 15 have a dementia diagnosis. These fifteen residents are cared for in a separate part of the building, where they eat and speand most of their time together. A gastvrouw/gastheer [a staff member responsible for providing breakfast and lunch, who, unlike the regular care staff, stays in the living room to spend time with 
residents and engage them in activities] was present from 8 a.m. until 4 p.m.. Dinner, cooked in the care home's kitchen, was handed out by the evening shift. Lastly, De Parkhoeve is a large-scale nursing home in an urban setting. Within the much larger nursing home, there are two floors for people with dementia who are classified as having 'heavy care needs', meaning that care for them includes staff with specific expertise, more technical aids (e.g. so-called passive hoists), and more staff than the care for residents classified who are classified as having 'lighter care needs'. Food was brought in from a kitchen elsewhere and heated up in food carts. The carers and nurses providing dinner were supported by a food assistant, often a student doing this work as a side job, and who was only there for a few hours each day. In total, the study included about 100 residents across the three sites, and about 60 care professionals (primarily care workers with different levels of training, the wards' care managers, physiotherapists, occupational therapists, doctors and psychologists). ${ }^{i v}$ Family members were included whenever they came to the care home.

Annelieke was present in each location for at least three days per week (mostly for the duration of one eight-hour shift) in the first ten weeks of fieldwork and at least two days per week after that. This article draws in particular on Annelieke's observations and participation during meal times. Annelieke served up plates, handed out food based on care workers' instructions, and baked eggs and pancakes (once, inadvertently, setting off the fire alarm). Care workers in the field sites were required to eat separately from residents as to be available for providing food and assistance to a resident group characterised by increasingly 'heavy' care needs. ${ }^{\vee}$ Annelieke sometimes did eat with residents, and assisted residents who required help to take in food in between and afterwards. This allowed her to observe interactions, and the lack thereof, during dinner and the ethical questions that are inherent to assisting somebody to eat. For instance, how to balance 'caring enough' and 'caring too much' when helping residents take food in (Schöller 2015)? What is the role of preferences, temperatures and texture in the refusal to eat (Harbers et al. 2002)? How much of the tastiness of the food can reasonably be sacrificed to facilitate food intake? Spending time with residents during dinnertime furthermore allowed Annelieke to become familiar with the difficulties that some 
residents experienced when handling rebellious noodles, and with the irritation this sometimes triggered when others read this as a lack of manners. She took detailed fieldnotes whenever possible, and elaborated these after leaving the field.

In De Zonneweide it was possible to conduct ten interviews with care workers, gastvrouwen/gastheren and one chef during work hours. Questions were based on observations, and pertained to doing daily care, the practical challenges and dilemmas therein, and ways to deal with them. The interviews with gastvrouwen/gastheren focused specifically on food work (see also Heaven et al. 2013), and how to 'know' and attend to food preferences. In De Parkhoeve, interviewing during work hours was not feasible due to changes in management and a staff shortage that resulted in increased work pressure. In order not to burden the staff with additional claims to their time, Annelieke therefore spoke to staff informally during care work and breaks. These countless informal conversations were recorded whenever appropriate and verbally consented to.

\section{Analysis}

All interview excerpts, parts of transcriptions of informal conversations and field notes were imported into the qualitative data analysis programme NVivo. We selected those pertaining to food provision, eating and drinking, to gain an understanding of how differences were attended to. While there were plenty of examples in which difference was not attended to, we have chosen to provide examples of situations in which different ways of doing difference did happen and became most clear. Thus, our theoretical intervention is not to offer a description of what food provision in residential care looked like to the ethnographer, but to aid a process of reflection and learning. To do justice to the difficulty of providing food in dementia care in the current circumstances, we also point out the potential limits of these practices, so that their fragility may be recognised.

Analytically, the idea was not to attend to the care of individual residents, but rather to disentangle different ways of attending to difference on the wards. This approach builds on the work 
of empirical ethicist and ethnographer Pols, who examines how citizenship is enacted in washing practices. She uses the term 'repertoires' for that which "brings together specific actions, ideals, and knowledge, forming 'modes of ordering'”vi (Pols 2006: 79-80). In each of Pols' four repertoires a different kind of citizen is enacted. Taking inspiration from this approach, we organised our material based on what was done in terms of attending to difference (actions), what kind of knowledge featured in these (inter)actions, and what was strived after (ideals), and what kinds of individuals are enacted. We present three repertoires of difference in the dementia care home. This is not meant as an exhaustive list. Indeed, as we found it impossible (and unproductive) to separate the repertoires completely, we offer these repertoires mostly as a device to think. In the conclusion we pay attention to how the repertoires may clash or harmonise, and draw lessons for care practice and researchers with regard to attending to difference.

\section{Repertoire 1: Providing Choice}

One way in which difference between individuals is enacted on the dementia ward is through providing choice. Countering a version of biomedicine in which patients are turned into passive objects, choice is widely celebrated as good. After all, "who likes to be dominated by others?" (Mol 2008: 1). ${ }^{\text {vii }}$ This emphasis coincides with a wider neo-liberal turn in health care practices in which independent choices are understood to lead to increased personal autonomy, and therewith to more active and independent individuals (Brannelly 2016). Yet, rather than in the dichotomous and agonistic contraposition of 'choice' as the opposite of 'care' that has become a common refrain in social science literature, we stage providing choice in dementia care as one of the many ways of doing care. In other words, attention to changing personal tastes and preferences is cared for through practices of providing choice.

In this repertoire what is valued is being able to choose for oneself, in order to be able to eat what one feels like having in a specific moment. viii Through choice, residents can differ from others in 
terms of preferences, and in how they can feel like eating different kinds of food at different points in time.

Institutions have come a long way in providing choice: many care workers told the ethnographer that until a decade earlier it was common to ask a new resident's family members what sandwich topping the person liked. Did somebody like cheese? They then received cheese on their breakfast toast for years on end. These days, choice is much more ingrained. For breakfast, for instance, there are different kinds of spreads on the table. And when care workers prepare sandwiches for the residents who cannot do so themselves, they ask what topping they would like. Asking is a technique to accommodate different tastes from what the menu has to offer. When offered a choice, residents can choose different foods - although from a limited set of options - at different points in time.

Importantly, choice requires people to be capable of making choices (Mol 2008: 6). However, that many people on the dementia ward have difficulty answering questions like "What would you like to eat?" shows that there are limits to verbalised choice. Therefore, unlike other wards where residents ticked boxes on a menu to indicate their dinner choice (albeit a few days in advance), on the dementia ward the menu of the day has two options for each component of the meal: two types of meat or fish, two types of vegetables, and potatoes, rice or noodles. When serving out food, care workers asked residents what they would like to have, but if they did not get an answer, they did not necessarily see this as an obstacle to attending to residents' tastes. Instead of offering choice verbally, then, they tried to find out what residents feel like eating. Consider this situation at lunch in De Parkhoeve:

Care worker Jantien serves pancakes to the residents. "Who would like a pancake with bacon?" she calls out. As is often the case when nobody is addressed directly, nobody answers. Sitting amongst the residents at the table, I ask Jantien what she does in these situations. "Oh", she answers, "I usually push [for an answer] ... and otherwise I know what residents like." I can observe how Jantien goes about this: She 
stands close to Ms Martens, makes eye contact, and asks, "What would you like on your pancake?" Ms Martens does not respond. Jantien lowers her face to Ms Marten's face and asks again. When still no answer follows, she asks, "Do you hear me?" Ms Martens says dryly: "I am listening", but nothing about bacon! Jantien asks her to say "Yes" if she wants bacon, and Ms Martens finally nods. After Jantien has brought over the pancake with bacon, she throws a few more glances in Ms Martens' direction to establish whether she is eating. When she does, Jantien concludes aloud that she was right in giving her bacon.

Jantien says that she knows what residents like. However, she asks Ms Martens again and again whether she wants bacon. When she does not get an answer, she remains in conversation, then tries out bacon and observes whether Ms Martens eats it. Trying and observing, then, is yet another technique with which to attend to individual tastes.

The individual that emerges from being given a menu, being asked for her preferences, and from being given some food to try whether she likes it, is an individual with tastes which may differ from one day to another: today, Mr Susila prefers bami-goreng (an Indonesian noodle dish) and Mr Kruijt takes the beef with mashed potatoes. Another day, both may opt for bami-goreng.

Importantly, providing choice is enabled but also constrained by institutional modes of attending to differences when other values take precedence. In the described situations, the menu affords choice between different kinds of food. If the choice is between two things that a resident does not particularly like, there is no other option. Mr Susila, for instance, no longer ate any of the food served on the ward, so his son brought him Indonesian take-away every single day. Here, providing choice is in tension with feasibility: not all family members can pay for take-away every day, let alone find the time to come to the nursing home at dinner time on a daily basis. Options on the menu simply cannot be endless, even if tastes may be. Furthermore, attending to some differences may thus take precedence over others: In De Parkhoeve, Ms Berg is the only one on the ward who 
eats halal. For her, there is halal meat, but nothing to choose from. The menu does not cater to religious obligations and choice simultaneously. Some differences thus get more attention than others. Similarly, residents can choose when to eat breakfast (there is flexibility between eight and ten a.m.), but clock time for dinner is fixed at 6 p.m., when the food is warm. Reheating the food later is not allowed due to food safety regulations. Here, values are in tension (Mol 2010): care for preferences and care for food safety. And institutionally, the latter is valued more, thus placing institutional restraints on residents' possibilities to enact their preferences about when to eat. ${ }^{\text {ix }}$

\section{Repertoire 2: Knowing residents}

The second repertoire of attending to differences is caring for somebody you know. Above we have seen that Jantien told the ethnographer that she knows what residents like to eat. Other care workers care for residents by giving them food to their liking. Mr Bakker was known for his love of tomato soup. Ms Rozendael loved anything sweet. ${ }^{\times}$Their caregivers knew this and provided these treats for them. They even took pleasure from knowing and organising these treats: Irene, gastvrouw in De Parkhoeve, said that finding out what residents like "makes working with people with dementia fun, as this is what we can get better at".

While the provision of choice allows residents to have various preferences at different times, here, care workers know about singular, and relatively stable tastes and habits. This knowledge has often been accumulated over years of caring for the same residents (and takes some time to be built when new resident are admitted to the ward). What has been found out in many previous encounters is trusted to be true for present encounters. Because it relies on a certain degree of stability, the individual is enacted as continuous - stretching from past into present. Yet, because this knowledge is continuously gathered and updated in talks with family members, and in interactions with residents, the individual enacted is relationally embedded. 
Some of these more stable differences are documented in patient files. Think, for example, of religious obligations, allergies and (in)abilities such as difficulties chewing or swallowing. Offering choice makes no sense in the face of these differences: asking Ms Van der Berg every day whether she eats halal would be nonsensical. The nursing staff cares for Ms Berg not by offering her a choice between halal and haram food, but by knowing that she eats halal. Other kinds of difference, in contrast, are not commonly written up, such as the quantities residents eat, and whether they eat better with a fork or a spoon. This kind of knowledge is most often gathered within relationships; it is intimate knowledge. In the words of Eline, gastvrouw in De Zonneweide:

You know your people! [Je kent je mensen!] Take Ms Verhagen, you go [to her table] and you make a sandwich, which you prepare right away, you see? But Ms Jacobs, I know that she is almost never hungry in the afternoon, because she likes snacking between meals. But [I know that] she eats enough. And in the evening she just eats a warm meal again.

Interestingly, knowledge about what residents liked did not have to be entirely individualised, as Cici, gastvrouw in De Zonneweide, emphasises:

I know for a fact that if you change the tastes that you offer people, they won't accept it. They go back to what they are used to from the past. Back then they had jam, apple juice, peanut butter and muisjes ${ }^{x i}$ but no bread with nuts or [drinks with] bubbles. ... When I make pancakes, I make them in the way they [people from this generation] are used to: not with pineapple or anything like that. They simply do not recognise it. So they won't eat it. I don't give it to them.

Knowledge of what a specific resident likes can therefore be derived from the history of a larger group, such as a generation. The knowledge of somebody's preferences or abilities may also pertain 
to individual bodies: when helping Ms Vrolijk to eat something in her very last days, care worker Leah said that she knew how to hold the spoon to Ms Vrolijk's lips so that she opened her mouth.

The skill of being sensitive to difference between residents becomes visible when newcomers, like the ethnographer in the first weeks of her fieldwork, or temporary care workers, do not know how to differentiate between different residents:

The two care workers and the food assistant working the evening shift in De Parkhoeve have to do their best to keep all residents at the table for dinner. In an attempt to make herself useful in serving up the plates, the ethnographer asks, 'How much for Mr Stuijt?' Ricky answers: 'That is too much food for him'. What follows are more determined instructions: 'Ms Berg gets halal food and it needs to be cut into small pieces. And add some more sauce, she likes that.'

The above example brings different differences to the fore: there are not only different kinds of food, but also different quantities, different ways of cutting, different amounts of sauce, and halal and haram food. Knowing how specific residents can take food in is important for doing food care as well. Leah tells the ethnographer that residents love the bami-goreng, especially Mr Susila, an IndonesianDutch resident. Yet, when there's bami for dinner again, he struggles to get the noodles onto his fork. His hand trembles so much that his fork arrives at his mouth empty. When Leah sees that he was given a fork, she says: "Oh, better give him a spoon!" Here it is neither about a choice for specific cutlery, nor about favouring one over the other. There is a practical concern. Leah compensates for Mr Susila's disability that his trembling hands represent, based on what she knows: by offering Mr Susila a spoon Leah offers him the possibility to eat in the way he is used to. This example is a case in point for the idea that individuality is dependent on the care that helps to realise it. Relationality, then, is a trait of independence, rather than a limitation to it (cf. Struhkamp 2005).

The ethnographer had to rely on those who know the habits, preferences and abilities of residents in order to help. This contradicts the idea that "anybody can provide food care" - an idea 
that seems to underlie hiring practices of untrained, temporary staff as food assistants. Food workers acquire and act on intricate knowledge about what and how individual residents eat. At the same time, this continuity is fragile. Eline again:

You must keep an eye on things. Indeed like "gosh, does someone not feel well?" When Ms Rozendael would suddenly say, "No, I'd rather not eat", then I'm going to pay attention, like 'Hey! What is going on?' Because she does not say that easily. Because that is just different per person. And they do not have to eat, but you just have to keep an eye on it: does it [Ms Rozendael eating little] stay this way? Is it just this once? ... Does she not like something? Can I offer her something else?

A temporary divergence is fine, but a longer break in routines and habits puts Eline on alert. 'Knowing one's people' thus provides a basis on which to signal when something is not quite right. Note that the difference here is not between individuals but within the same person over time: it demarcates the person in the present from that same person in the past - and it may hint towards a possible problem that needs assessment. Not eating does not necessarily mean someone is choosing not to eat, but rather that they require a critical eye as to 'what may be going on'. At the same time, choice is not entirely erased: nobody is forced to eat. Rather, different explanations are sought as to why somebody is not eating in the first place.

The work of attending to differences through 'knowing residents' is easily overlooked and devalued. In De Parkhoeve all gastvrouwen/gastheren were made redundant just months after the fieldwork ended. Indeed, when they were let go, care workers took over this work in addition to their tasks to get residents up and washed. This limited the possibility to observe residents, and to invest in the relationship that provides the basis for knowing somebody. The gastvrouwen/gastheren were hired back after just a few months. The care organisation learned the hard way: knowing residents is a skill that relies on care workers' sensitivity to differences. This sensitivity is crucial to doing care well, and it is not easily acquired. 


\section{Repertoire 3: Catering to identities}

The third repertoire of attending to difference is 'Catering to identities'. Care workers do this by temporarily suspending their knowledge about a resident's preferences, habits and the like. In other words, they temporarily stop knowing, and tap into what is emergent in order to 'know anew'. The alertness to preferences and habits and possible changes to these becomes particularly relevant in dementia care, because many kinds of (rapid) changes may occur as part of the condition. Following the observation of change, care workers may adapt to accommodate new habits (Aneshensel et al. 1995: 349).

What is valued here is the recognition of fluidity. That accommodating change in this manner is not always easy was most dramatically illustrated when Ms Jansen, who had been a vegetarian for most of her adult life, took and ate meatballs from the plate of her neighbour at the table, and was found eating them with great appetite. This seemingly small incident became a big cause for tension. Care staff felt committed to letting Ms Jansen enjoy meat; after all, she seemed not to mind eating it, and yes, even to love it. Was care not about providing people with some pleasure in their last days? Ms Jansen's family members, in contrast, were absolutely against this. They argued that she would have never wanted this, and, by extension, neither did they. The care staff, however, were reluctant to prioritise the resident's former commitment to not eat meat as voiced by the family members, over the resident's current preferences.

Vegetarianism is an example of a food habit or preference that provides some sort of stability to individuals (Klein 2008). These eating habits turn vegetarians into who they are (as, similarly, eating halal is part of Ms Berg's religious identity). Because care workers do not share a long history with the person with dementia, it is generally less emotional for them to accommodate a change to something that was once such a big part of somebody's daily life and identity than it is for family members and partners who have shared a life together. Family members may hold on to what somebody liked and 
did in the past, while caregivers are better positioned to accommodate discontinuity. A change might be particularly emotional for family members because it plays out in parallel with many other changes that characterise the progression of dementia. Family members and partners might feel that their loved one has changed to a degree that they no longer recognise them as themselves (Taylor 2008). This becomes most obvious in remarks that people make about their relative or partner with dementia that express a sense of estrangement from them, such as "she is not my mother anymore" or "the person I got married to is no longer there" (cf. Lemos Dekker 2016). The family members' emotions in situations like this should not be underestimated. As a care worker put it aptly: "The whole sadness of that family may be in that meatball". xii

Ms Jansen's case draws attention to an interesting tension: sometimes knowing the resident's past may help to provide care and to understand a resident better. Sometimes, it may complicate things instead. The tension highlights a challenge which characterises dementia care more broadly: is somebody who he or she was before, or has he or she become somebody else? But rather than a philosophical and abstract question, again, there it is a practical concern: what should be done? Should the meatballs be served to this particular resident, or not?

While Ms Jansen's family members attended to Ms Jansen's former habits, care staff attended to the changed preferences. They allowed her to have a fluid identity, to be different from others, but also from herself in the past. Tensions between one individual at different moments are never quite resolved, and so practicing difference can be a continuous and fraught process.

The limits to this repertoire, then, come in the form of questions that can only be answered case by case in practice: which and how much change can family members live with? What would make the perceived losses more bearable? (Partial) Solutions can be found in communication that extends beyond the residents with dementia to their relationships. In this particular instance, family members and care workers agreed to give Ms Jansen vegetarian meatballs. 


\section{Mixing repertoires}

The call to tailor care to individuals in health care is growing louder. But to what differences should care be tailored? And how may this be done? In this article, we described three repertoires of attending to difference through food provision in dementia care: providing choice, knowing residents, and catering to identities. In each of these repertoires, differences are something different. 'Providing choice' pertains to what kind of food somebody may feel like at one particular moment. The menu, asking and observing may be ways to attend to this. 'Knowing residents' meant knowing someone's love or distaste for a particular food and caring for the continuity of tastes and habits. Clues about these may be taken from interactions with residents and their biographies as told by family members and friends who visit them on the ward. In the repertoire we called 'catering to identities', what is at stake is who someone is. Drastic changes may be too painful to bear, or they become a source of conflict. Which differences are attended to, and how this is done, then, matters for the way in which individuals are enacted.

While we have separated these repertoires of attending to difference heuristically, in practice they may overlap, co-occurring harmoniously or even clashing. Ms Weinaart had only moved into the care home the week before when she told the ethnographer during fieldwork that she only liked sandwiches with chocolate sprinkles [hagels/ag] for breakfast. Afraid of depriving her of the possibility to have something else in case she felt like it, the ethnographer continued to put the basket with the assortment of bread spreads on the table where Ms Weinaart sat. After a few days, Ms Weinaart snapped at her: "I told you I only like hagelslag! No need to bring me all that other stuff". This incident points to the impossibility of attending to differences in one single 'right way'. If having one's preferences known leads to receiving the same sandwich topping for years, choice is a liberation. If being served what one likes without being asked is a form of recognition, and a way to say 'I know you', choice may undo this. Being asked again and again may prove a nuisance and, indeed, a denial of relationships that have been established before. What is right, then, depends on the situation. 
Repertoires may also harmonise: knowing somebody often goes together with providing choice, such as when care workers know that a particular resident likes to make her own choices. Here is one last story, from the ethnographer's first day in De Bostuin:

I am seated beside Mr Steven at the breakfast table. He puts one layer of butter after another on his slice of bread. Iris looks over, but continues to help Mr Black with making his sandwich. After careful consideration Mr Steven picks the apple syrup from the selection of toppings, and puts the jar down next to his plate. He continues to look around the table. After a minute or so Iris asks him, "What would you like on your sandwich?" Mr Steven then picks up the peanut butter, opens it, smells it. "Urgh". Iris points out the apple syrup next to his plate. Mr Steven looks at it blankly. "Do you want that?" Iris asks. "Yes", he says. When Iris asks if she can help him, he nods. She gets up, spreads out the butter and puts some apple syrup on the very edge of the slice of bread, and sits back down next to Mr Black. Mr Steven just cuts it into uneven pieces, smearing the syrup over his entire plate. Although he 'failed' to spread out the syrup, Iris intervenes no more. xiii $^{\text {in }}$

Afterwards, Iris explained why she did what she did (and refrained from doing anything): $\mathrm{Mr}$ Steven's wife had often interfered with his ways. He could still be very irritated about things that she had decided for him, for instance when Iris pointed out the clothes that his wife had bought for him, he said, quite agitatedly, "Oh, my wife!" Iris said she prefers to give Mr Steven some more time before interfering with his actions, or not to do so at all.

All three repertoires are inextricably interwoven here: Mr Steven can choose a topping from the set of spreads on the table. Iris acts on her knowledge of his biography (precisely by waiting as long as possible). She allows time for him to change his mind, as to know anew. Only in the last moment does she interfere in the least invasive way possible, putting apple syrup on the side of the sandwich, for him to spread out, or not. The story shows that differences are not stable (preferences and abilities 
may change), nor do they add up coherently (past convictions may not be the same as current appreciations). Insisting on continuity risks rigidifying somebody's tastes or habits, causing a loss of openness to new preferences, or the possibility of forming new habits. By contrast, attending to change, incoherence and discontinuity allows somebody to become different from before. But here the risk is to lose what was key to somebody's identity, which can be painful for those who have known the person in question for a long time.

\section{Food matters for individual difference}

We began this article by reviewing how in different medical settings attention to individuality takes the shape of focusing on genetic difference, variation in personal circumstances, subjective experiences, and diverging psychological needs. These are laudable attempts to bring a more efficient, compassionate and tailored care to institutional settings. Implicit in these ways of conceptualising the individual were differences between groups. In this paper we have attended to individuality and differences as enacted in food provision practices in Dutch residential care. We here conceptualise 'individuality' as made evident and enacted in practice. Individuality is not merely an ethical and philosophical problem, but also a practical one for those working and living in institutional environments. Our empirical material and analysis demonstrate that much can be learned from how food workers do individuality, by enacting differences between residents - even different kinds of difference - and differences within residents over time. We have shown this work to be deeply relational, for residents are active in their own enactments as individuals. We show that in food provision practices, it may not always be categories that matter most (a resident being vegetarian), but an attentiveness to residents' past and present actions that can inform practical care decisions. The dilemma is then what to tailor care to, when different kinds of differences are in tension.

Building on the work of empirical ethicist and ethnographer Pols, we have disentangled different ways of attending to difference on the ward, which we have presented as repertoires. It is our 
analytical intervention to bring to the fore those moments in which individuality is attended to in different ways, to hold them up as examples, but also to outline their potential limits. Thus, our theoretical intervention is not just to describe, but to demonstrate the positive impact of attending to differences. This brings to the fore relationality, and the impossibility of making a fixed rule of what individuality and personhood might be in care settings.

To return to the questions with which we began, we conclude by suggesting three implications of our analysis for thinking about individuality and difference. Firstly, our analysis shows that making differences is not easy. It requires work, work that consists of offering options, observing responses, and keeping options open. With regard to this point in particular, when the gastvrouwen/gastheren were let go, and their tasks had to be taken up by care workers, the underlying message from the institution seemed to be that food work is not important enough to be supported financially. However, as we have shown, much gets lost with these jobs, not least the knowledge of residents built up by those providing food - which we have shown to be crucial in enacting individuality.

Secondly, our analysis brings individuality to the fore as a relational process. Institutions enact certain kinds of individuals, and foreclose the enactment of others: the institutional menu caters to various tastes, religious identities, and abilities, but caters much less to choice in terms of what to eat if one's preference is not one of the two options served, or when to eat, or cultural differences. Individuals, in our analysis, are not isolated entities, but are enacted through the practices of paying attention to difference: providing choice enacts residents as able to express preferences themselves, sometimes verbally, sometimes non-verbally. In our analysis, 'choice' does not emerge as the opposite of 'care'. While providing choice is frequently assumed to be a universal good, our analysis highlights these practices as just one of the ways of caring for differences and individuality. Knowing residents places emphasis on the care providers' actions instead, but is based on existing relationships. Catering to identities enacts (changing) tastes as part of individuality. Individuality thus comes about in relations: individuals are made in practices of relating people to other people, to objects, or to a narrative of their past behaviours, tastes and desires. This analysis links with and 
strengthens the argument that insists on personhood as characterized by relationality, rather than linked to cognitive abilities (e.g. Gjødsbøl and Svendsen 2018). It furthermore underscores the argument that material conditions are important for how care can be done (Buse et al. 2018; Twigg and Buse 2013; Van Hout et al. 2015).

Thirdly, our analysis teaches us that tailoring care is not necessarily about how differences can be attended to, but also what kind of difference are attended to. Sometimes individuality is related to groups (or sameness, if you will), such as when populations, generations or cultural groups are defined, and individuals are examples of these groups. But groups do not make individuals, as individuals may differ in yet other ways (vegetarians who eat meat for instance). This is a relevant finding for researchers as well. There is a realisation that the terms used in relation to differences are not merely descriptors but play a role in stabilising and naturalising some categories and contesting others (Krebbekx 2018; Krebbekx et al. 2017). In doing research, we thus do not only describe, but create and recreate certain differences and categories. It is therefore urgent to ask which categorisations are strengthened in practices of making differences, and which are weakened. It is our hope that our analysis will foster researchers' increased sensitivity toward ways in which differences and particularities are attended to.

\footnotetext{
' Our own understanding of dementia builds on Kitwood's thinking about relationality, but places an additional emphasis on materiality, and to how people with dementia are themselves active in these relations.

ii We leave open what 'dementia' is. See Moser (2008) for an analysis of the different 'mattering' of dementia.

iii All names, of residents and field locations, are pseudonyms.

iv Exact numbers are difficult to provide: the number of residents and staff changed throughout the research period.

${ }^{\vee}$ After policy changes to the admission requirements for residential care in the Netherlands in 2014 and 2015, the field sites under study underwent a process 'institutional densification': an increase of the resident population's infirmity (Higgs and Gilleard 2015, 14).

vi Pols draws here on the work of Law on 'modes of ordering' (1994). See for a further development of this concept Moser (2005), Vogel (2014) and Krause (n.d.).

vii In 'The Logic of Care' Mol (2008), for analytical purposes, contrasts choice with care. Here, we make a version of choice visible as a form of care.

viii In practice, making choices oneself turns out to be dependent on quite a lot of arrangements and work from others (see for instance Buuse 2017; Driessen 2017; Struhkamp 2005).

ix In De Bostuin, Mr Barend liked to eat later than the institutional schedule prescribed. Care staff managed to extend the options available to him by ensuring that he could eat in the restaurant.

${ }^{\times}$Gastvrouwen/gastheren and care workers may find themselves in situations where they must set limits to residents' intake of their favourite food or drink. To provide residents with the food and drink they love is a central concern of food workers in dementia settings, but so is setting boundaries when, for example, a
} 
resident suffering from diarrhoea forgets that she has already had coffee, or a resident with diabetes whose love for pudding puts her at risk of a hypo.

${ }^{x i}$ Muisjes (literally 'little mice') are sugar-coated coloured aniseeds. Muisjes are sometimes eaten with a regular breakfast, but are more readily associated with the Dutch custom, dating back to the $17^{\text {th }}$ century, of serving rusk with muisjes to visitors who come to see a newborn.

xii xii This comment was made in one of the workshop sessions of the conference Goed Leven met Dementie: Hoe doen we dat? ['Living well with dementia: how do we do that?'], organised by the Long-Term Care and Dementia team at the University of Amsterdam in June 2017. During this workshop session people working or living with dementia discussed a case comparable to the one presented. See for a report of this conference Amsterdam Care Collective (2018).

xiii Those reading earlier drafts of this paper asked us whether what Annelieke observed could have been a performance, suggesting that care workers were 'showing off' to her at 'being a good care worker'. This is at best a cynical reading of the data as it suggests that care workers do not 'care' in the affective sense of the word, a sentiment that is very much fueled by the ever-present critique of institutional care. Here, we do not deny that there were indeed instances in which food provision happened in a quick and careless way, with little attention to personal specificity, but insist on shifting the focus to instances in which differences were attended to, to learn how it may be done.

\section{References}

Abbott, R. A., Whear, R., Thompson-Coon, J., Ukoumunne, O. C., Rogers, M., Bethel, A., and Stein, K. (2013) Effectiveness of mealtime interventions on nutritional outcomes for the elderly living in residential care: a systematic review and meta-analysis, Ageing Research Reviews, 12, 4, 967-81. https://doi.org/10.1016/j.arr.2013.06.002.

Amsterdam Care Collective. (2018). Dementia and the good life: Collaborations with the field.

Medicine Anthropology Theory. Retrieved from

http://www.medanthrotheory.org/read/10021/dementia-and-the-good-life

Aneshensel, C. S., Pearlin, L. I., Mullan, J. T., Zarit, S. U., and Whitlach, C. J. (1995) Profiles in

Caregiving: The Unexpected Career. San Diego, CA: Academic Press.

Balint, E. (1969) The possibilities of patient-centered medicine, Journal of the Royal College of General Practitioners, 17, 82, 269-76.

Bonnel, W. B. (1993) The nursing home group dining room: managing the work of eating, Journal of Nutrition for the Elderly, 13, 1, 1-10. https://doi.org/10.1300/J052v13n01_01.

Brannelly, T. (2016) Citizenship and people living with dementia: a case for the ethics of care,

Dementia, 15, 3, 304-14. https://doi.org/10.1177/1471301216639463.

Brijnath, B. (2011) Alzheimer's and the Indian appetite, Medical Anthropology, 30, 6, 610-28. https://doi.org/10.1080/01459740.2011.582473.

Buse, C., Martin, D., and Nettleton, S. (2018) Conceptualising 'materialities of care': making visible 
mundane material culture in health and social care contexts, Sociology of Health and IIIness, 40, 2, 243-55. https://doi.org/10.1111/1467-9566.12663.

Buuse, S. van den. (2017) Zelfredzaamheid en eigen regie in het verpleeghuis: Goede zorg voor mensen met dementie? In A.-M. The, R. Pool, and J. Pols (eds.) Goed Leven Met Dementie: Dialoog Tussen Wetenschap En Praktijk. Amsterdam: Ben Sajetcentrum \& Universiteit van Amsterdam, pp. 41-4.

Day, S., Coombes, R. C., McGrath-Lone, L., Schoenborn, C., and Ward, H. (2017) Stratified, precision or personalised medicine? Cancer services in the 'real world' of a London hospital, Sociology of Health and IIIness, 39, 1, 143-58.

Driessen, A. (2019). On building-user interactions: how sociomaterial awareness enables ways of living well in dementia care homes. Forthcoming in Medical Anthropology. Published online 19 April 2019 ('Dementia matters: user-building interactions shaping institutional life in the Netherlands'). https://doi.org/10.1080/01459740.2019.1589464.

Driessen, A. (2017). Sociomaterial will-work: aligning daily wanting in Dutch dementia care. In J. Boldt \& F. Krause (eds.) Care in Healthcare: Reflections on Theory and Practice. London and New York: Palgrave Macmillan, pp. 111-33.

Driessen, A. (2019). A good life with dementia: Ethnographic Articulations of Everyday Life and Care in Dutch Nursing Homes. University of Amsterdam. Retrieved from https://dare.uva.nl/search?identifier=dd0c2b9b-348d-4de8-9747-84363846fdd0

Gjødsbøl, I. M., and Svendsen, M. N. (2018) Recognizing dementia: constructing deconstruction in a Danish memory clinic, Medical Anthropology Quarterly, 32, 1, 103-19. https://doi.org/10.1111/maq.12365.

Harbers, H., Mol, A., and Stollmeyer, A. (2002) Food matters: arguments for an ethnography of daily care, Theory, Culture and Society, 19, 5-6, 207-26. https://doi.org/10.1177/026327602761899228.

Heaven, B., Bamford, C., May, C., and Moynihan, P. (2013) Food work and feeding assistance on hospital wards, Sociology of Health and IIIness, 35, 4, 628-42. https://doi.org/10.1111/j.14679566.2012.01515.x.

Henkusens, C., Keller, H. H., Dupuis, S., and Schindel Martin, L. (2014) Transitions to long-term care: how do families living with dementia experience mealtimes after relocating?, Journal of Applied Gerontology, 33, 5, 541-63. https://doi.org/10.1177/0733464813515091.

Higgs, P., and Gilleard, C. (2015) Rethinking Old Age: Theorising the Fourth Age. London and New York: 
Palgrave Macmillan.

Hughes, J. C., Bamford, C., and May, C. (2008) Types of centredness in health care: themes and concepts, Medicine, Health Care and Philosophy, 11, 4, 455-63. https://doi.org/10.1007/s11019008-9131-5.

Kitwood, T. (1993) Person and process in dementia, International Journal of Geriatric Psychiatry, 8, 541-45. https://doi.org/10.1002/gps.930080702.

Kitwood, T. (1995) Positive long-term changes in dementia: some preliminary observations, Journal of Mental Health, 4, 133-44.

Kitwood, T. (1997) Dementia Reconsidered: The Person Comes First. Maidenhead: Open University Press.

Klein, J. A. (2008) Afterword: comparing vegetarianisms, South Asia: Journal of South Asian Studies, 31, 1, 199-212. https://doi.org/10.1080/00856400701874767.

Krause, K. (2018) Speaking from the blind spot: political subjectivity and articulations of disability. Critical African Studies, 10, 3, 287-300. https://doi.org/10.1080/21681392.2019.1610012

Krebbekx, W. (2018) Making sex, moving difference: schools, an ethnography of sexuality and diversity in dutch schools, PhD thesis, University of Amsterdam. Retrieved from http://dare.uva.nl/search?identifier=068b6d6f-d5a5-4555-b594-3a308744576b.

Krebbekx, W., Spronk, R., and M'charek, A. (2017) Ethnicizing sexuality: an analysis of research practices in the Netherlands, Ethnic and Racial Studies, 40, 4, 636-55. https://doi.org/10.1080/01419870.2016.1181771.

Law, J. (1994) Organizing Modernity. Oxford: Blackwell.

Lemos Dekker, N. (2016) Beyond Social Death: New Socialities in Everyday Life with Dementia, paper presented at the 115th Annual Meeting of the American Anthropological Association, Minneapolis, MN, 16-20 November 2016.

Milte, R., Shulver, W., Killington, M., Bradley, C., Miller, M., and Crotty, M. (2017) Struggling to maintain individuality - describing the experience of food in nursing homes for people with dementia, Archives of Gerontology and Geriatrics, 72, 52-8. https://doi.org/10.1016/j.archger.2017.05.002.

Mol, A. (2008) The Logic of Care: Health and the Problem of Patient Choice. London: Routledge. Mol, A. (2010) Care and its values. Good food in the nursing home. In A. Mol, I. Moser, and J. Pols 
(eds.) Care in Practice: On Tinkering in Clinics, Homes and Farms. Bielefeld: transcript Verlag, pp. 215-34.

Moser, I. (2005) On becoming disabled and articulating alternatives. The multiple modes of ordering disability and their interferences, Cultural Studies, 19, 6, 667-700.

https://doi.org/10.1080/09502380500365648.

Moser, I. (2008) Making Alzheimer's disease matter. Enacting, interfering and doing politics of nature, Geoforum, 39, 98-110. https://doi.org/10.1016/j.geoforum.2006.12.007.

Pols, J. (2006) Washing the citizen: washing, cleanliness and citizenship in mental health care, Culture, Medicine and Psychiatry, 30, 1, 77-104. https://doi.org/10.1007/s11013-006-9009-z.

Reimer, H. D., and Keller, H. H. (2009) Mealtimes in nursing homes: striving for person-centered care, Journal of Nutrition for the Elderly, 28, 4, 327-47. https://doi.org/10.1080/01639360903417066.

Schöller, Y. D. (2015) Setting norms or negotiating feasibility? On eating enough in a care home, research Master thesis, University of Amsterdam. Retrieved from http://www.scriptiesonline.uba.uva.nl/570857.

Struhkamp, R. M. (2005) Patient autonomy: A view from the kitchen, Medicine, Health Care and Philosophy, 8, 1, 105-14. https://doi.org/10.1007/s11019-004-1134-2.

Taylor, J. S. (2008) On recognition, caring, and dementia, Medical Anthropology Quarterly, 22, 4, 31335. Retrieved from http://doi.wiley.com/10.1111/j.1548-1387.2008.00036.x.

Twigg, J., and Buse, C. (2013) Dress, dementia and the embodiment of identity, Dementia, 12, 3, 32636. https://doi.org/10.1177/1471301213476504.

Van Hout, A., Pols, J., and Willems, D. (2015) Shining trinkets and unkempt gardens: On the materiality of care, Sociology of Health and IIIness, 37, 8, 1206-17. https://doi.org/10.1111/14679566.12302 .

Vogel, E. (2014) Clinical specificities in obesity care: the transformations and dissolution of 'will' and 'drives', Health Care Analysis, 24, 4, 321-37. https://doi.org/10.1007/s10728-014-0278-3.

Vogenberg, F. R., Barash, C. I., and Pursel, M. (2010) Personalized medicine. Part 1: evolution and development into theranostics, Pharmacy and Therapeutics, 35, 10, 560-76.

Watson, R. (1993) Measuring feeding difficulty in patients with dementia: perspectives and problems, Journal of Advanced Nursing, 18, 25-31.

Watson, R., and Green, S. M. (2006) Feeding and dementia: a systematic literature review, Journal of Advanced Nursing, 54, 1, 86-93. https://doi.org/10.1111/j.1365-2648.2006.03793.x. 